\title{
Study on the Off-campus Base Construction of Innovative Experimental Areas for Legal Talent Cultivation
}

\author{
Xu Huijuan \\ Law School, Hunan University of Technology, Zhuzhou, 412007, China
}

Keywords: legal talents; cultivation; innovative experimental areas; off-campus base construction

\begin{abstract}
The off-campus base construction of innovative experimental areas for legal talent cultivation is a new field that is totally different from the theoretical teaching of ordinary colleges and has its own distinct characteristics. The off-campus bases of innovative experimental areas for legal talent cultivation should regard cultivating professional legal talents as their major objective, and the course arrangement, base construction, software and hardware construction, etc. should be carried out ion the basis of this idea, so as to achieve the effective connection between legal theoretical and practice courses and form a favorable occupational atmosphere. The national education development plan requires to vigorously cultivate students' spirit and thinking of innovation and improve their abilities of practice, creation and entrepreneurship. In order to persist in the employment-oriented direction, it is required to continuously update the teaching contents, improve the education and teaching methods and enhance learners' abilities of practice, vocation and employment. Therefore, the author explores the issue about off-campus base construction of innovative experimental areas for legal talent cultivation, centering on how to cultivate legal talents' practical ability, vocational skills and employability.
\end{abstract}

\section{Basic characteristics of off-campus bases of innovative experimental areas for legal talent cultivation}

The first one is the practicality. This is a basic characteristic that the off-campus bases of innovative experimental areas for legal talent cultivation should be equipped with. The off-campus bases should assume this function as it is one of the major sites for guiding learners' practical teaching and internship. The second one is the openness. This requires that the off-campus bases of innovative experimental areas for legal talent cultivation should not operate in an enclosed way, but strengthen the connection with other groups, organizations and the society, practically enrich and improve the practical teaching through such connection, and assume the function of cultivating off-campus talents on the basis of cultivating in-college talents. The third one is the technicality. Considering that the training contents should be advanced, the off-campus base construction of innovative experimental areas for legal talent cultivation should lay emphasis on the technicality that the practical teaching should be equipped with. The reasonable application of advanced technologies and equipment can provide high-quality services for legal practical teaching and legal talent cultivation. The fourth one is the specialization. In the training course of the law major, the off-campus bases assuming the practical training task must have corresponding qualifications, so as to provide support for students' practice in terms of law major.

\section{The urgency to carry out the off-campus base construction of innovative experimental areas for legal talent cultivation}

Firstly, it is required by education of the law major. The law major in colleges has a very strong practicability, and the specific teaching contents and methods should be continuously enriched and improved based on this characteristic of the law education. Currently, although there are courses with strong practicability such as law clinic and moot court that are set for the law major, their proportions are very low. The practical education link has not met students' needs and the teaching objectives, which results in disconnection between theoretical teaching and practical teaching. The off-campus bases of innovative experimental areas for legal talent cultivation that are built upon 
long-term cooperation can solve the previous problem of insufficient practical teaching, and is a prominent means for enriching and improving the teaching contents and methods of the law major.

Secondly, it is one of the ideas to solve the problems of difficulty in financing and lack of double-capacity teachers. Implementation of the practical teaching requires not only the corresponding funds for support, but also the professional law teachers with good theoretical knowledge and practical ability. Certainly, as the law education in our country is very large in size, the input of teaching funds is extremely insufficient, which brings trouble to the law major in many colleges. Meanwhile, the extremely insufficient proportion of double-capacity college teachers in our country restricts the practical teaching from obtaining a new development in our country. The above-mentioned problems lead to the fact that the practical education can not favorably meet college students' learning demands and the teaching objectives. In the face of this situation, various social resources should be utilized in a proper and comprehensive way to smoothly solve this problem. Establishing the off-campus bases of innovative experimental areas for legal talent cultivation can effectively mitigate the problem of insufficient input of funds for practical training and consequently provide students with a better opportunity for participating in the practical training. In the meantime, instructing teachers for the off-campus bases of innovative experimental areas for legal talent cultivation can cover the shortage that college teachers have insufficient experience in practice. Although some college teachers for the law major also serve as part-time lawyers, their experience in practice is still insufficient comparing with that of professional lawyers. Of course, some college teachers even have never got in touch with the law practice work. Relying on Establishment of off-campus bases of innovative experimental areas for legal talent cultivation can not only cover the shortage, but also let teachers get practice.

Thirdly, it is an important attempt to meet the needs of college students majoring in law. Both the cultivation objective of college students majoring in law and the expected learning objectives of students require considerable abilities for practice and practical application. Once the law education separates from the reality and fails to properly combine the theory and the practice, college students may lose their learning initiative and then lose their learning motivation, which will affect their future employment. Establishing the off-campus bases of innovative experimental areas for legal talent cultivation has provided modern college students majoring in law with an opportunity to really get in touch with practice, and can motivate them to apply their learned theoretical knowledge into the practice. In this way, it can not only stimulate college students' strong interest in learning and guide them to make a plan for their future occupational careers in a better way, but also let them bring the difficulties encountered during practice back to the classroom for thinking, which will promote the theoretical teaching of the law major in colleges, further deepen the college students' impression on the classroom teaching of law.

\section{Steps for off-campus base construction of innovative experimental areas for legal talent cultivation}

Firstly, it is required to make a targeted selection of the construction unit for off-campus bases of innovative experimental areas for legal talent cultivation. The major purpose of establishing off-campus bases of innovative experimental areas for legal talent cultivation is to cultivate college students' abilities of practice, vocation and employment. Therefore, the selection and construction of off-campus bases of innovative experimental areas for legal talent cultivation should center on the theme of cultivating professional legal talents. In the course of selecting the base construction unit, it is required to not only highlight the requirements and characteristics of the law major, but

also give consideration to college students' employment. For this purpose, selection of the construction unit for off-campus bases of innovative experimental areas for legal talent cultivation should give priority to the local public security or judicial organs or judicial administrative organs, especially to the procuratorates or courts. As the above-mentioned units have relatively concentrated and rich cases and their prosecutors and judges have extremely rich experience in practice, college students of law major can get in touch with more knowledge about legal practice. Besides, when selecting off-campus bases of innovative experimental areas for legal talent 
cultivation, attention may be also paid to law firms and relevant advisory organs involved in legal affairs, as they can provide college students of law major with the opportunity to carry out the legal practice. In the course of selecting the construction unit for off-campus bases of innovative experimental areas for legal talent cultivation, it is also required to consider whether the construction unit meets corresponding conditions for cultivating, educating and exercising the college students of law major, for example, whether the construction unit can provide college students with the opportunity for participating in all kinds of specific practice and possesses high-quality instructors with corresponding legal knowledge and practical experience, and whether the leaders of the construction unit cooperate with and pay attention to such work.

Secondly, it is required to sign a long-term cooperation agreement with the construction unit. After selecting and earnestly negotiating with the construction unit for off-campus bases of innovative experimental areas for legal talent cultivation, a long-term cooperation agreement should be signed between both parties. This agreement should define the responsibilities and obligations to be borne by both parties in the course of establishing off-campus bases of innovative experimental areas for legal talent cultivation, the guarantee system to operate the off-campus bases of innovative experimental areas for legal talent cultivation, and relevant cooperation carried out by both parties based on the off-campus bases of innovative experimental areas for legal talent cultivation. On the basis of signing the cooperation agreement, establishing a long-term cooperative relationship with the construction unit for off-campus bases of innovative experimental areas for legal talent cultivation can not only effectively promote the progress of the practical teaching activity for the law major, but also timely promote and popularize colleges' images, and deepen the communication and cooperation among colleges, judicial practice organs, enterprises and public institutions.

Thirdly, it is required to formulate specific management systems for off-campus bases of innovative experimental areas for legal talent cultivation. After confirming the construction unit for off-campus bases of innovative experimental areas for legal talent cultivation and signing the cooperation agreement, specific and feasible management systems should be prepared for the actual operation of these bases. The above-mentioned systems are used mainly for managing and assessing those students coming into these bases for study, and are also used for making clear the management responsibilities and cultivation obligations assumed by both parties.

Fourthly, it is required to designate the management organization and its personnel responsible for operating the off-campus bases of innovative experimental areas for legal talent cultivation. As for the management organization established by a college for off-campus bases of innovative experimental areas for legal talent cultivation, its responsible person should be the college's relevant leader, and full-time management personnel should be arranged in the base management organization. Management personnel of off-campus bases of innovative experimental areas for legal talent cultivation are mainly responsible for communicating with the base construction unit, managing and applying the funds for the bases, arranging and preparing the activities to be conducted at these bases, allocating corresponding instructors, organizing college students for training, etc.

\section{Policies to further promote the off-campus base construction of innovative experimental areas for legal talent cultivation}

(I) Forming a "double-capacity" teacher group that combines off-campus part-time and in-college full-time teachers

The responsible person for off-campus bases of innovative experimental areas for legal talent cultivation and front-line business backbones should be employed as practice instructors. Besides that judges, prosecutors and other officials serve as members of the off-campus specialist instruction committee and periodically take part in teaching and instructing activities, a large number of front-line business backbones with practical work experience should be also employed as teachers for practical training at the bases. Meanwhile, judges with rich teaching experience should be employed to assume practical training and teaching tasks in the college, to take part in preparing practical training instruction materials and to hold lectures related to legal affairs. The people's 
assessors in courts, part-time lawyers in law firms and full-time teachers with experience in judicial work should be also employed as "double-capacity" teachers as far as possible to assume the teaching of relevant practical training courses and consequently meet the requirements of college courses of law major on instructing teachers and finally achieve the teaching objective of one-to-one practical training.

(II) Carrying out the substituted post exercitation based on engineering combination

The substituted post exercitation mode combining the off-campus engineering should be implemented as of the second term of the freshman year. It is required to periodically select and send probationers to all off-campus bases of innovative experimental areas for legal talent cultivation, and one or two months of substituted post exercitation may be carried out in each term; in-college teachers and instructors of these bases are responsible for students' education, teaching, attendance checking, assessment, etc. College students should carry out the work with the role of employees in the probation unit, and their behaviors should meet the rules and regulations of the probation unit. For example, probationers should favorably accomplish all kinds of works such as visitor reception, legal consultation, drafting various legal documents, assisting lawyers in investigation, assisting in appearance in court and binding materials in the case when they are in a judicial department, legal assistance center, law firm or people's court. With the substituted post exercitation, college students can improve their knowledge on judicial organs and consequently exercise their abilities of utilizing various administrative office equipments, business consultation, preparing legal documents, practical computer operation, etc.

(III) Devoting to achieving the close connection between basic theoretical course and legal practice course

As for the law major in colleges, the connection between basic theoretical course and legal practice course can be accomplished from the following two aspects. On one hand, special and basic theoretical courses should be well completed, namely, the connection between basic theoretical courses of law major and various special courses; on the other hand, the close connection between basic theory of law major and actual practice should be well completed. Relatively, the latter is assumed mainly by the same teachers and the mutual connection can be achieved in a easier way, while the former is assumed by different teachers in terms of the legal course arrangement and it is difficult to achieve the actual close connection. For this reason, it is required to strengthen the compulsive connection between this two situations, achieve scientific and standardized course arrangement and teaching contents, and explore the specific teaching link.

\section{Conclusion}

To sum up, strengthening the off-campus base construction of innovative experimental areas for legal talent cultivation is an important way to speed up the legal talent cultivation by utilizing social resources in a comprehensive way. Therefore, we should continuously summarize and improve the advance experience, so as to give better play to the effect of off-campus bases of innovative experimental areas for legal talent cultivation.

\section{Acknowledgments}

This paper is the research achievement from the educational reform subject of Hu'nan Province: Research on Construction of Practicing and Teaching Bases on the Basis of Outstanding Legal Talent Cultivation; project number: Xiang Jiao Tong [2014] No. 247-318

\section{Bibliography}

[1] Gao Huiyun, Discussion on Legal Issues in Operation of Colleges' Productive Training Bases, [J]. China Modern Educational Equipment, 2012 (21).

[2] Liu Pei and Yao Shuyuan, Research on Construction of Law Colleges' Training Bases, [J]. legality Vision (mid-month version), 2013 (2). 
[3] Che Yifei, Research on Construction of Higher Vocational Colleges' Practical Training Bases Effective Promotion of Construction of Higher Vocational Colleges' Practical Training Bases by Implementing Vocational Education Related Laws and Regulations, [J]. Heilongjiang Science, $2013(9)$

[4] Han Fengran, Research on Construction of Higher Vocational Colleges' Practical Training Base System, [J]. Journal of Hebei Youth Management Cadre Institute, 2013 (15). 